\title{
"They Deserved It": Using the Just World Hypothesis to Understand Victim Blaming, Apathy, and Support on Social Media
}

\author{
Laurie Giddens \\ Southern Illinois University Edwardsville \\ lgidden@siue.edu
}

\author{
Stacie Petter \\ Baylor University \\ Stacie_Petter@baylor.edu
}

\begin{abstract}
Social media offers a forum for individuals to share experiences after being wronged by an individual, an organization, a group, or a government. While some individuals gain support through sharing experiences on social media, other victims become the subject of attacks or receive little to no response from others regarding their injustice. An individual's response to a victim's social media post may be explained by the just world hypothesis. In this article, we explain the just world hypothesis and how this theory applies to when individuals respond to victims on social media. The just world hypothesis offers a means to understand factors that encourage negative social media behaviors. In this conceptual article, we explain how future research may leverage the just world hypothesis as a theoretical lens to examine why individuals engage in victim blaming, victim apathy, or victim support using social media.
\end{abstract}

\section{Introduction}

In recent years, scholars have acknowledged that while information technology (IT) can bring about benefits to organizations and individuals, there are also negative impacts, or a "dark side" of IT use. Research examining the "dark side" of IT use often encompass negative behaviors and reactions, such as technostress, information overload, technology addictions, anxiety, and IT misuse [12, 54]. "Dark side" research includes the study of the negative aspects of IT in the workplace $[2,19,62]$ as well as the "dark side" of hedonic technologies, such as social media [65].

Social media offers an area ripe for exploration of "dark side" behaviors because the number of social media platforms and number of social media users. Estimates suggest social media users around the world reached 3.5 billion in April 2019 [16], and the extensive use of social media technology worldwide has a tremendous impact on individuals and society. Research on the dark side of social media use have studied social media addiction [51, 65], stress [23], and cyberbullying and harassment $[7,21]$.

Social media organizations often purport the value of their organizations to connect individuals or to enable individuals to express themselves. For example, the mission statement for Facebook is "Give people the power to build community and bring the world closer together" [20]. Twitter states, "We believe in free expression and think every voice has the power to impact the world" [66]. Tencent, the owner of WeChat, says that its mission is "to improve the quality of life through internet value-added services" [63].

To some extent, social media organizations have delivered on these values by allowing for the development of important social movements. For example, social media has provided a platform to help individuals rise up against social and political injustices [60], such as the Arab Spring in 2011 [53]. Social media has also empowered communities during natural disasters, such as the Thailand Flood [39]. Many individuals use social media to share their experiences, seek out information, connect with others, and find social support [17]. Social media is a forum that can connect individuals to bring about social change (or not) [67] or can enable discourse on topics that may be emancipatory or hegemonic [50].

Yet, while social media offers some individuals and groups emotional and social support and connections, others experience blame or apathy from others on social media when seeking support related to a victimizing experience or a social movement. Some individuals share tragic experiences through social media, such as those who posted videos and pictures when Southwest Airlines flight \#1380 in danger of crashing. These social media posts received a variety of responses ranging from empathy to ridicule. Social movements in which victims have shared their collective experiences on social media, such as Black Lives Matter, \#MeToo, or \#TimesUp have been met 
with both support from the general public as well as negative responses.

While research has considered how social media features can promote collective action for positive impacts [53], new lenses and theories can shed light on why social media users choose to blame, ignore, or support victims or social movements on social media. To examine the reasons why individuals engage in harmful behaviors on social media, we need a theoretical lens that explains why individuals may engage in negative discourse. In this research, we introduce the just world hypothesis to understand how people respond to social media posts and calls for social movements online.

The just world hypothesis asserts that individuals make sense of injustices in the world by assuming that victims are getting what they deserve [42]. Research examining the just world hypothesis (also referred to as Belief in a Just World) has considered perceptions about victims among jurors [22], opinions of victims of bullying in school [15], and views regarding organizational justice in the workplace [35]. The just world hypothesis explains why individuals sometimes blame or ignore victims or social movements on social media.

The research objective of this conceptual paper is to illuminate the rationale for negative behavior using the just world hypothesis. Through this understanding of the just world hypothesis, future research can explore how social media affordances may contribute to or negate the effects of the just world hypothesis.

The next section provides a description of the just world hypothesis by describing the theory, its assumptions, and key constructs. Next, we offer a discussion of the affordances provided by social media and how the just world hypothesis is applicable in the context social media. Finally, we offer an agenda for future information systems (IS) research using the just world hypothesis and social media affordances to study victim blaming, apathy, and support on social media.

\section{Just world hypothesis}

The just world hypothesis, devised by Melvin Lerner, states that "Individuals have a need to believe that they live in a world where people generally get what they deserve" [42:1030]. This hypothesis proposes that individuals believe in a just world to explain events in the world that directly affect people's fate. Individuals recognize that the world is not always just or fair; however, the belief that individuals tend to get what they deserve enables individuals to maintain a level of perceived control over the outcome of their pursuits and function in society [40].
More specifically, the just world hypothesis explains and predicts human reactions to victims of injustice. Lerner describes feelings of injustice as "the violation of that which is judged to be appropriate" [40:10]. The tendency of humans to make a judgement about what should be the consequence of an event is a common reaction to one's environment. When individuals see victims of human suffering or injustice, it violates the belief that the world is just, which can lead individuals to react to a perceived injustice with fury, outrage, and indignation [40, 42]. When an individual observes another's unjust suffering, it imposes the idea that the observer might also be a victim of injustice [41]. The observer's just world view becomes challenged, and s/he will seek to rectify the situation by intervening to restore justice. However, if observers are unable to restore justice to the victim, the observer will respond cognitively by aligning the situation with their belief in a just world [10:288].

By connecting an individual's circumstance to their own actions or moral character, the observer can then perceive the situation as just or fair, thereby reducing the negative dissonance experienced when one's belief in a just world is threatened [31]. As such, individuals who have convinced themselves that a victim is deserving of the injustice and responsible for his/her own misfortune may respond by derogating, or blaming, the victim [42]. This response is known as the derogation effect and is well-established in social psychology literature $[10,25,41]$. Blaming a victim is a common response to observed suffering in the world when one is not able to restore justice [28, 31, 43].

Victims may engage in self-derogation to resolve the cognitive dissonance that occurs when the victim cannot explain their circumstance. Self-derogation, or blaming oneself for being a victim, has been noted among those imprisoned in Nazi concentration camps [5] and rape victims [44]. In these instances, victims employ self-derogation as a means to cope with the overwhelming idea that their suffering could happen to innocent people [42].

To trigger the derogation effect, (1) the victim must be innocent of the injustice that has occurred, (2) the observer must relate to the victim's circumstances (i.e. the situation could happen to them), and (3) the observer must be unable to restore justice to the victim $[40,43]$. An individual's belief in a just world, which influences the derogation effect, becomes threatened under certain conditions. When observers encounter victims who experience continuous or prolonged suffering after a harmful event, individuals' just world beliefs are threatened [28]. For example, observers may view a person who becomes a quadriplegic after a drunk driver causes an accident as experiencing 
significant suffering. Threats to just world beliefs are raised when the perpetrator of harm has not been brought to justice [28]. Moreover, just world beliefs are threatened when the observer cannot change what happened to the victim or restore justice [6]. When these circumstances are present, threats to just world beliefs are high, and observers are more likely to derogate the victim. When this occurs, victims suffer from the original victimizing event and again when they are blamed for their plight [34].

The just world hypothesis explains the derogation effect in response to victims to those in poverty [26, 52], AIDS patients [36], and rape victims [22, 44]. The extent to which an individual believes in a just world is affected by a person's personality traits, such as authoritarianism and internal locus of control [27, 57] and religious participation and conservative political views [3].

Although belief in a just world is associated with negative outcomes (i.e. derogation effect), there are also positive outcomes associated with an individual's beliefs in a just world [10, 25]. Belief in a just world serves to shield individuals from the reality of harsh, unjust life circumstances by allowing people to keep their beliefs and thus preserve their well-being [61]. Those who have a high belief in a just world minimize unfairness and are less angry at unjust events [9] and have higher levels of trust in individuals and social institutions [3]. Moreover, those with high beliefs in a just world are less likely to engage in deviant behavior [14] as they believe that good deeds are rewarded [10]. Thus, belief in a just world is not a negative belief system, but a deep-rooted belief system that individuals have a strong need to protect. Individuals will protect their just world beliefs when threatened with injustice as a protection mechanism against the idea they could experience the same fate [25, 42]. Outside of social psychology, the just world hypothesis has been applied to a variety of contexts and domains including political science [4, 52], criminal justice [11], management [35], and marketing $[68,69]$. Despite the extensive application of the just world hypothesis across domains, this theoretical lens is underutilized in informing IS research.

\section{Social media and just world hypothesis}

\subsection{Social media affordances}

Numerous affordances of social networking sites are identified in extant literature [30, 38, 46, 64] with the majority of research focusing on enterprise social media. Treem and Leonardi [64] identify four affordances of enterprise social media: visibility, editability, persistence, and association. These affordances are posited to impact behaviors in organizations, such as socialization and knowledge sharing practices. Identifyability and networked information access are additional affordances that influence online group discussion processes [30]. Table 1 defines selected social media affordances from the literature. These affordances provide a foundation to deepen our current understanding of the use of social media by victims and respondents.

Table 1. Affordances of social media.

\begin{tabular}{|l|l|}
\hline Affordance & Definition \\
\hline Visibility & $\begin{array}{l}\text { The ability of social media to make } \\
\text { users' behavior, knowledge, and } \\
\text { network connections that were } \\
\text { previously invisible, visible [64] }\end{array}$ \\
\hline Editability & $\begin{array}{l}\text { The ability of users to edit content that } \\
\text { is collaboratively created online [64] }\end{array}$ \\
\hline Persistence & $\begin{array}{l}\text { The ability of social media to provide } \\
\text { continuous access to previously } \\
\text { created content [64] }\end{array}$ \\
\hline Association & $\begin{array}{l}\text { The ability of social media to help } \\
\text { users create and maintain relationships } \\
\text { between people and between people } \\
\text { and information [64] }\end{array}$ \\
\hline Identifyability & $\begin{array}{l}\text { The ability of social media to identify } \\
\text { individual users [30] }\end{array}$ \\
\hline $\begin{array}{l}\text { Networked } \\
\text { information } \\
\text { access }\end{array}$ & $\begin{array}{l}\text { The ability of social media to provide } \\
\text { access to multiple networks of } \\
\text { information [30] }\end{array}$ \\
\hline
\end{tabular}

\subsection{Terminology}

Just world hypothesis research often refers to a victim, who has experienced a harmful event or been subject to a negative outcome. Observers become aware of the victim because of a stimulus, which can be due to direct observation of a victimization, reading a scenario, or exposure to information through newspapers or television [29]. In this research, we focus on social media as the stimulus that makes others aware of the victim, even though the initial victimization may occur online or offline.

An observer may or may not blame the victim for the victimization that occurred, depending on the observer's level of belief in a just world [45]. The observer may engage in no action or may choose to become a contributor regarding the victimization by responding on social media. The contributor may respond through offering support to the victim or by engaging in blaming of the victim.

Within the context of social media, there are several types of victimization. In the examples discussed below, there is an initial, or primary, victimization in which a person becomes a victim. However, if victim blaming occurs, the victim 
experiences a secondary victimization resulting from the backlash experienced on social media [72]. Table 2 provides a summary of this terminology that we use to explain the application of the just world hypothesis in the context of social media.

Table 2. Key terms and definitions.

\begin{tabular}{|l|l|}
\hline Term & Definition \\
\hline Victim & $\begin{array}{l}\text { The individual who is the subject of a } \\
\text { negative or harmful event }\end{array}$ \\
\hline Stimulus & $\begin{array}{l}\text { Prompt that enables others to realize } \\
\text { that a person is a victim or that a } \\
\text { victimization has occurred }\end{array}$ \\
\hline Observer & $\begin{array}{l}\text { An individual that has obtained } \\
\text { knowledge about a victim and his/her } \\
\text { victimization }\end{array}$ \\
\hline Contributor & $\begin{array}{l}\text { An observer that chooses to speak out } \\
\text { regarding the victim or victimization } \\
\text { through support or blaming }\end{array}$ \\
\hline Response & $\begin{array}{l}\text { The post on social media made by a } \\
\text { contributor regarding a victim's } \\
\text { experience }\end{array}$ \\
\hline $\begin{array}{l}\text { Primary } \\
\text { Victimization }\end{array}$ & $\begin{array}{l}\text { The initial harm experienced by the } \\
\text { victim that was initially observed by } \\
\text { others }\end{array}$ \\
\hline $\begin{array}{l}\text { Secondary } \\
\text { Victimization }\end{array}$ & $\begin{array}{l}\text { Additional harm or negative events } \\
\text { that occur after observers or } \\
\text { contributors engage in blame or } \\
\text { apathy }\end{array}$ \\
\hline
\end{tabular}

\subsection{Victimization stimuli on social media}

There are several ways in which individuals become observers of a victim's circumstance using social media.

3.3.1. Victim shares experience on social media. In some cases, an individual may share their story of victimization through social media. For example, passengers on Southwest Airlines Flight 1380 on April 17,2018 thought that their plane was about to crash after an engine exploded and depressurized the cabin. One passenger purchased in-flight Wi-Fi to share his final moments with loved ones using live streaming on social media. Other passengers posted pictures and messages on social media as the pilots and crew worked to safely land the plane. The plane landed safely (with one fatality), but the passengers and crew on this flight were victims of a horrific experience mid-flight (i.e., primary victimization). However, many passengers, including the one who livestreamed the final moments of the flight, became the subject of a secondary victimization after being ridiculed on social media for the act of livestreaming or posting the event on social media [32].
3.3.2. Contributor offers victim support on social media. Others share their prior victimization on social media to offer support for others. When several actresses shared stories of sexual assault by a popular Hollywood producer, Alyssa Milano, a well-known actress, encouraged victims of sexual assault to use the hashtag \#MeToo [58]. Milano became a contributor to encourage others to support victims of sexual assault. While many victims felt strong support through the \#MeToo movement on social media [47], others expressed concerns that privately, observers may be blaming these victims [48].

3.3.3. Victim learns of victimization on social media. Sometimes a victim is unaware of the primary victimization until the event is shared on social media. One example of this scenario is revenge pornography, which occurs when a person posts sexually explicit images or videos online of another individual without their knowledge or permission [1]. The images are most often posted by a former intimate partner. One victim, known as "Jane," recounted her experience when an ex-boyfriend posted nude photos of Jane on the website, UGotPosted. Jane consented to her boyfriend taking the pictures of Jane when they were dating. After the couple stopped dating, the exboyfriend posted these pictures online. Jane received phone calls, emails, and social media friend requests from hundreds of people that primarily solicited her for sex [73]. The aftermath of revenge porn can have devastating psychological effects on the victims [1].

3.3.4. Secondary victimization occurs on social media. Sometimes news events make a victimization public and contributors respond via social media. In a highly publicized case, a 13-year old girl in the United States was raped by two 18-year old high school students in 2013. While the victim did not share her victimization on social media, people in the community came to the defense of the men charged with the crime and blamed the young victim on Twitter [71]. In this case, not only was the young girl a victim of rape, but she was victimized again when the community blamed her and her family for the legal problems of the perpetrators.

\subsubsection{Secondary victimization occurs on social} media (without primary victimization). Some individuals become the victims of trolling attacks. For example, Leslie Jones (an actress) was inundated on Twitter and other social media sites with hateful memes, racist comments, and other vulgarities after the release of her movie, Ghostbusters, in 2016. As a result, Twitter permanently banned Milo 
Yiannopoulos, who instigated many of the vulgar social media attacks against Leslie Jones [33]. Many individuals supported Leslie Jones during these online attacks, but others viewed Yiannopoulos as the victim and either expressed support for Yiannopoulos as a victim or further attacked Leslie Jones online.

\subsection{Responses to victims}

The just world hypothesis contends that individuals try to reconcile unexplainable events that happen to victims using two primary methods: (1) restoration of justice or (2) derogation of the victim [42]. We propose that when social media is the stimuli in which an observer learns about a victimization, this may affect the nature of the observer's response (or lack of response). Furthermore, social media affordances may explain why individuals apply the just world hypothesis in social media contexts.

3.4.1. Victim blaming. When an observer learns about a victim due to a stimulus, the observer may believe the victim is responsible to varying degrees for their victimization [59]. When an individual is perceived as having some level of responsibility for his/her victimization, this is known as victim blaming (or victim facilitation or victim precipitation) [18]. Victim blaming occurs in a variety of contexts. For example, a study of rape culture in social media forums revealed that $25 \%$ of all comments made on articles discussing rape blamed the victim [72].

Observers often blame victims if the victimization is severe and the chance of restoring justice is low [10, 68]. For example, when there is a large number of victims or the victimization is the result of a wicked problem that cannot be easily addressed (i.e. poverty, climate change, war refugees), observers may feel that interventions to restore justice are futile and resort to re-interpreting the situation to ascribe blame to the victim to maintain their belief in a just world. Studies indicate that people are more likely to respond to appeals for help when the need is low [49, 68]. Further, research indicates that individuals will utilize emotion-based coping mechanisms to deal with situations in which they have little control over the outcome [24].

The inability to restore justice may be a reason for an observer to become a contributor on social media to blame a victim. However, victim blaming on social media may be more related to individual attributes of the observer and the level of belief in a just world. Research indicates that individuals with a high belief in a just world are associated authoritarian beliefs [57], conservative views [52], religious participation [3], and internal locus of control (personal agency) [27,
57]. Therefore, as observers tend to be more authoritarian, conservative, religious, and believe in internal locus of control, there tends to be higher levels of victim derogation. Thus, some observers who possess these traits are more likely to continue to blame a victim using social media.

Social media affordances relevant to victim blaming include visibility and persistence. On social media, individuals may observe many victims of social injustice, which can make it feel impossible for observers to restore justice. As individuals make their experiences visible to others (i.e., visibility) and because the information can be accessed over time (i.e., persistence), observers may struggle to identify how justice can be restored.

In the Black Lives Matter social movement in the United States, many victims of police injustice or brutality felt a sense of empowerment or agency by sharing their experiences and gaining support through social media [70]. The issues represented by the social movement of Black Lives Matter represents the intersection of many groups and problems within the United States, such as prejudice, race relations, relationships between local communities and law enforcement, and local and federal laws. Some observers have never been subject to prejudicial experiences with law enforcement and do not understand what the victims have experienced. Consequently, these observers do not view the victims as suffering harm and have no need to restore justice [57]. Others cannot imagine a solution to these complex problems within the United States. When observers cannot identify a solution, then observers tend to look for other reasons to explain world events by blaming the victim [42].

In an extreme case of the social media affordance of identifyability, Diamond Reynolds livestreamed the shooting death of her boyfriend, Philandro Castille, by a police officer at a traffic stop while she was in the car. She became one of the many faces of the Black Lives Matter movement. Yet, given the extreme scenario (i.e., a man stopped for a broken taillight was killed by a police officer), many looked for reasons to blame Castille for his outcome. The mass media revealed that Castille had been stopped by police dozens of times and that there was suspicion of Castille being part of a recent armed robbery. Because social media affords identifyability, critics on social media could then look for reasons to blame Castille or Reynolds for their victimization. When individuals could not explain why a law enforcement officer would shoot and kill an innocent man at a traffic stop, the just world hypothesis explains this reaction by many as a need to make the victim responsible for the injustice to make things "right with the world." 
To reduce an observer's propensity toward the just world hypothesis, one can create more similarities between observers and victims using the social media affordance of association. The law enforcement officer claimed that one reason he stopped Castille and Reynolds was because Castille resembled someone that committed a recent armed robbery. Since most observers have not been accused of looking like someone that has committed an armed robbery, there would be less sympathy and more potential for victim blaming. However, if the narrative about Castille had focused on him being stopped for a broken taillight (a situation that may occur for any person that owns a car), then this may have led to less blaming of the victim.

3.4.2. Victim apathy. When victims are perceived to have a level of responsibility for their victimization, observers may respond differently to the victim. Some may choose to ignore the victim while others fail to act to support the victim by engaging as a bystander [37].

The just world hypothesis suggests that observers would not engage if they did not feel it is possible to restore justice or if the victim does not deserve their support [40]. A study of adolescents found that individuals tend to remain a bystander when someone is a victim of cyberbullying partly due to the observer's perception that there is little ability to intervene [13]. Other research suggests that when individuals feel powerless to change the outcome for good, they will avoid making a decision about the situation [8]. This type of belief suggests that the observer perceives little ability to restore justice and therefore chooses not to engage. If the observer felt more empowered to make a difference (to the victim or to restore social justice), then the just world hypothesis would have a smaller effect.

While social media offers the affordance of association to create relationships, it may be that this affordance is not utilized by observers with a strong belief in a just world. Furthermore, the persistence affordance of social media may also numb observers to victims' experiences, which may lead to apathy if there appears to be no way to restore justice to the victim.

3.4.3. Victim support. According to the just world hypothesis, a person will seek to restore justice if they feel the victim is innocent [41]. Thus, in the case of victim support in the context of social media, observers may choose to contribute and support a victim if one or more of the following is perceived to be likely: (1) the victim is perceived to be innocent by the observer; (2) the observer feels empowered that their supportive contribution will restore justice to the victim; or (3) the observer does not rely on the just world hypothesis to make sense of the world [6].

For example, when a stalker secretly recorded and posted videos of an ESPN reporter, Erin Andrews, on social media, some people (often anonymously) criticized the videos for their quality or lack of content in the video. Yet, there was a large outcry in support of Andrews for this invasion of her privacy [55]. For many, Andrews' victimization, in which she was filmed through the peephole of a hotel room, was a scenario that could happen to anyone. When observers can characterize a smaller distance between the victim and themselves, this leads to higher levels of victim support.

There are also studies that suggest that not everyone relies on the just world hypothesis to make sense of the unexplained circumstances in the world [56]. If individuals have other means to "restore justice" (e.g., forgiveness), then this urge to blame a victim for their circumstance is not needed by the observer [61]. Additionally, if an observer does not view the victim as suffering or if the observer is connected to or strongly identifies with the victim, then the just world hypothesis will not be exhibited [42]. Social media has provided the means to offer some individuals a sense of empowerment through sharing their experiences with others online. In social movements, those that have been victimized and can share their experiences through a social movement, such as \#MeToo, \#TimesUp, or \#BlackLivesMatter, individuals have an opportunity to use their victimization or their past experiences to demonstrate support for other victims. These types of contributions offer observers a means to make a difference through social support to restore a sense of justice in the world.

The social media affordance of association can be particularly strong for supporters. Being able to identify as part of a group or social movement can be a reason why individuals may contribute support to a victim. Visibility, identifyability, or networked information access are social media affordances that may encourage support for victims or social movements on social media.

\section{Developing a research agenda for the just world hypothesis and social media}

In this paper, we offer a lens to examine social media behaviors. The just world hypothesis can illuminate our understanding of why some victims or social movements receive support from contributors online, why some victims are blamed on social media, and why some victims are ignored. Understanding the just world hypothesis, in conjunction with social 
media affordances, is useful to develop a series of topics for a research agenda regarding how individuals engage with victims and social movements on social media.

The just world hypothesis has the potential to explain individual's behaviors online as they observe victims. The types of research methods used may include experiments, observations of social media posts, or interviews with users to understand behaviors on social media. Table 3 provides ideas of research questions to study the application of the just world hypothesis and social media affordances.

Table 3. Sample research questions for social media affordances and the just world hypothesis

How does the medium (e.g. video, text, memes, pictures, or combination) and the affordances of the medium used as a stimulus affect responses to the victim?

How does visibility of victim postings impact the number and type of responses?

How does identifyability of the victim impact the number and type of responses?

What social media affordances provide observers the ability to restore justice to victims?

Are there characteristics of the victimization, the victim, or the affordances used on social media to communicate information about the victimization that lead to higher perceptions of (a) restoration of justice or (b) derogations of victims?

Does the number of contributions or intensity of contributions affect the responses of observers?

How does an observer's or contributor's identifyability affect their willingness to engage through victim support or victim blaming?

How does the design of social media platforms and the affordances enabled by the platform encourage or discourage sympathy for victims (which may lead to increased support and less blame)?

What features and affordances of social media or content contributions are associated with secondary victimization and why?

By using social media as a context to study the just world hypothesis, there is also the potential to consider how we might intervene to enable victims to have the ability to garner the support needed. Using research, it may be possible to offer techniques, such as design science research or action interventions to reduce the just world hypothesis for observers. We offer these research questions to encourage research to creatively consider how we might encourage more victim support. As an example, assume there is a group seeking to gain support to eliminate children being forced to participate in military action. This group may find difficulty in finding support among observers. By understanding how to craft appeals that may reduce the derogation of the victim or may encourage sympathy among the victims, the movement may find more support for their cause.

Beyond the sampling of research questions provided in Table 3, there are many other possibilities for research related to the just world hypothesis in the context of social media and/or information systems. The suggestions above offer just a few examples of the opportunities to examine how individuals respond to victims online.

Throughout this paper, we share many examples of victims online; however, we found few citations related to these or other similar types of events in IS research. One reason may be due to the length of the publication process. However, we also boldly suggest an alternative reason regarding why we do not study these behaviors on social media. As researchers, we, too, may believe the just world hypothesis. We may choose to avoid certain phenomena, particularly in terms of how technology may empower victims or marginalize others, because of our belief in a just world. There are many difficult issues and wicked problems that we tend to grant little attention to within IS research, such as online sex trafficking, cyberbullying, and trolling, among other topics. We encourage researchers to consider topics that might be ignored because in the back of our minds we may not see victims, but rather people "that deserved it."

\section{Conclusion}

As we study the "dark side" of IT use or social media, there are many more opportunities available for research. Beyond the traditional topics of dark side IT use, such as technostress, information overload, technology addictions, and anxiety [12, 54], our research introduces the just world hypothesis to understand why individuals may choose to support, ignore, or blame victims. We argue that the social media behaviors of ignoring or blaming victims can also be part of the "dark side" of IT use.

Through this research, we explain the just world hypothesis as well as provide examples of how this lens is applicable in the study of behaviors on social media. By understanding the derogation effect and its triggers, researchers can explore how users of social media might mitigate this effect. While most of our examples are related to individual victims, this lens could explain why some social movements gain traction online while others fail to gain momentum.

We also acknowledge that "victim" is in the eye of the beholder. As in the earlier example of Leslie Jones, while we believe that Ms. Jones was the victim, others view Yiannopoulos as the victim for being banned 
from social media. There can be situations in which it is not clear exactly who the victim is. Our assumption is that to support a victim, one does not need to berate, disparage, or victimize another. We also wish to note that that as we conduct research related to victims on social media, we should take care to avoid secondary victimization of a victim. Our research questions should not suggest that the victim's communication of their victimization is the reason for victim blame or apathy. There is also a need to take care in explaining or providing evidence of victimization that occurs in social media to avoid new trolling or negative responses toward the victim because of our research.

As social media creates different ways to create positive discourse that empowers and connects, social media also creates divisions and marginalizes through negative or "dark side" behaviors [50]. In our work, we demonstrate the value of using a different lens to understand how we can explain social media behaviors and offer ideas for additional research to promote more positive interactions online.

\section{References}

[1] Bates, S., "Revenge Porn and Mental Health: A Qualitative Analysis of the Mental Health Effects of Revenge Porn on Female Survivors", Feminist Criminology 12(1), 2017, pp. 22-42.

[2] Bawden, D., and L. Robinson, "The dark side of information: overload, anxiety and other paradoxes and pathologies", Journal of Information Science 35(2), 2009, pp. 180-191.

[3] Bègue, L., "Beliefs in justice and faith in people: just world, religiosity and interpersonal trust", Personality and Individual Differences 32(3), 2002, pp. 375-382.

[4] Bénabou, R., and J. Tirole, "Belief in a Just World and Redistributive Politics", The Quarterly Journal of Economics 121(2), 2006, pp. 699-746.

[5] Bettelheim, B., "Individual and mass behavior in extreme situations", The Journal of Abnormal and Social Psychology 38(4), 1943, pp. 417-452.

[6] van den Bos, K., and M. Maas, "On the Psychology of the Belief in a Just World: Exploring Experiential and Rationalistic Paths to Victim Blaming", Personality and Social Psychology Bulletin 35(12), 2009, pp. 1567-1578. [7] Casas, J.A., R. Del Rey, and R. Ortega-Ruiz, "Bullying and cyberbullying: Convergent and divergent predictor variables", Computers in Human Behavior 29(3), 2013, pp. 580-587.

[8] Chatzidakis, A., S. Hibbert, and A.P. Smith, "Why People Don't Take their Concerns about Fair Trade to the Supermarket: The Role of Neutralisation", Journal of Business Ethics 74(1), 2007, pp. 89-100.

[9] Dalbert, C., "Beliefs in a Just World as a Buffer Against Anger", Social Justice Research 15(2), 2002, pp. 123-145. [10] Dalbert, C., "Belief in a Just World", In M.R. Leary and R.H. Hoyle, eds., Handbook of Individual Differences in Social Behavior. Guilford Publications, 2013.
[11] Dalbert, C., and E. Filke, "Belief in a Personal Just World, Justice Judgments, and Their Functions for Prisoners", Criminal Justice and Behavior 34(11), 2007, pp. 1516-1527.

[12] D'Arcy, J., A. Gupta, M. Tarafdar, and O. Turel, "Reflecting on the 'Dark Side' of Information Technology Use", Communications of the Association for Information Systems 35, 2014.

[13] Desmet, A., C. Veldeman, K. Poels, et al., "Determinants of self-reported bystander behavior in cyberbullying incidents amongst adolescents", Cyberpsychology, behavior and social networking 17(4), 2014, pp. 207-215.

[14] Donat, M., C. Dalbert, and S.V. Kamble, "Adolescents' cheating and delinquent behavior from a justice-psychological perspective: the role of teacher justice", European Journal of Psychology of Education 29(4), 2014, pp. 635-651.

[15] Donat, M., A. Wolgast, and C. Dalbert, "Belief in a Just World as a Resource of Victimized Students", Social Justice Research 31(2), 2018, pp. 133-151.

[16] Edison Research, and Salesforce.com, "Percentage of U.S. population who currently use any social media from 2008 to 2019", Statista, 2019.

https://www.statista.com/statistics/273476/percentage-ofus-population-with-a-social-network-profile/

[17] Eichhorn, K.C., "Soliciting and Providing Social Support Over the Internet: An Investigation of Online Eating Disorder Support Groups", Journal of ComputerMediated Communication 14(1), 2008, pp. 67-78.

[18] Eigenberg, H., and T. Garland, "Victim Blaming", In L.J. Moriarty, ed., Controversies in Victimology. 2008.

[19] Elie-Dit-Cosaque, C., J. Pallud, and M. Kalika, "The Influence of Individual, Contextual, and Social Factors on Perceived Behavioral Control of Information Technology: A Field Theory Approach", Journal of Management Information Systems 28(3), 2011, pp. 201-234.

[20] Facebook, "Facebook", Facebook, 2019.

https://www.facebook.com/pages/category/Website/facebo ok/about/

[21] Fenaughty, J., and N. Harré, "Factors associated with distressing electronic harassment and cyberbullying", Computers in Human Behavior 29(3), 2013, pp. 803-811. [22] Foley, L.A., and M.A. Pigott, "Belief in a Just World and Jury Decisions in a Civil Rape Trial", Journal of Applied Social Psychology 30(5), 2000, pp. 935-951. [23] Fox, J., and J.J. Moreland, "The dark side of social networking sites: An exploration of the relational and psychological stressors associated with Facebook use and affordances", Computers in Human Behavior 45, 2015, pp. $168-176$

[24] Frantz, C.M., and F.S. Mayer, "The Emergency of Climate Change: Why Are We Failing to Take Action?", Analyses of Social Issues and Public Policy 9(1), 2009, pp. 205-222.

[25] Furnham, A., "Belief in a just world: research progress over the past decade", Personality and Individual

Differences 34(5), 2003, pp. 795-817.

[26] Furnham, A., and B. Gunter, "Just world beliefs and attitudes towards the poor", British Journal of Social Psychology 23(3), 1984, pp. 265-269. 
[27] Furnham, A., and E. Procter, "Belief in a just world: Review and critique of the individual difference literature", British Journal of Social Psychology 28(4), 1989, pp. 365384.

[28] Hafer, C., "Do Innocent Victims Threaten the Belief in a Just World? Evidence From a Modified Stroop Task", Journal of Personality and Social Psychology 79(2), 2000, pp. $165-173$.

[29] Hafer, C., and L. Be'gue, "Experimental Research on Just-World Theory: Problems, Developments, and Future Challenges", Psychological Bulletin 131(1), 2005, pp. 128 167.

[30] Halpern, D., and J. Gibbs, "Social media as a catalyst for online deliberation? Exploring the affordances of Facebook and YouTube for political expression", Computers in Human Behavior 29(3), 2013, pp. 1159 1168.

[31] Harber, K.D., P. Podolski, and C.H. Williams, "Emotional disclosure and victim blaming", Emotion 15(5), 2015, pp. 603-614.

[32] Hay, A., "Southwest passenger trolled for livestreaming stricken flight", Reuters, 2018.

https://www.reuters.com/article/pennsylvania-airplanesocialmedia-idUSL1N1RV232

[33] Isaac, M., "Twitter Bars Milo Yiannopoulos in Wake of Leslie Jones's Reports of Abuse", The New York Times, 2017.

https://www.nytimes.com/2016/07/20/technology/twitterbars-milo-yiannopoulos-in-crackdown-on-abusivecomments.html

[34] Janoff-Bulman, R., C. Timko, and L.L. Carli, "Cognitive biases in blaming the victim", Journal of Experimental Social Psychology 21(2), 1985, pp. 161-177. [35] Johnston, C.S., F. Krings, C. Maggiori, L.L. Meier, and M. Fiori, "Believing in a personal just world helps maintain well-being at work by coloring organizational justice perceptions", European Journal of Work and Organizational Psychology 25(6), 2016, pp. 945-959. [36] Kogut, T., "Someone to blame: When identifying a victim decreases helping", Journal of Experimental Social Psychology 47(4), 2011, pp. 748-755.

[37] Latane, B., and J.M. Darley, "Bystander 'Apathy", American Scientist 57(2), 1969, pp. 244-268.

[38] Leidner, D.E., E. Gonzalez, and H. Koch, “An affordance perspective of enterprise social media and organizational socialization", The Journal of Strategic Information Systems 27(2), 2018, pp. 117-138.

[39] Leong, C., S. Pan, P. Ractham, and L. Kaewkitipong, "ICT-Enabled Community Empowerment in Crisis Response: Social Media in Thailand Flooding 2011", Journal of the Association for Information Systems 16(3), 2015.

[40] Lerner, M.J., "The Belief in a Just World", In M.J. Lerner, ed., The Belief in a Just World: A Fundamental Delusion. Springer US, Boston, MA, 1980, 9-30.

[41] Lerner, M.J., "The Two Forms of Belief in a Just World", In L. Montada and M.J. Lerner, eds., Responses to Victimizations and Belief in a Just World. Springer US, Boston, MA, 1998, 247-269.
[42] Lerner, M.J., and D.T. Miller, "Just world research and the attribution process: Looking back and ahead", Psychological Bulletin 85(5), 1978, pp. 1030-1051.

[43] Lerner, M.J., and C.H. Simmons, "Observer's reaction to the 'innocent victim': Compassion or rejection?", Journal of Personality and Social Psychology 4(2), 1966, pp. 203-210.

[44] Libow, J.A., and D.W. Doty, “An exploratory approach to self-blame and self-derogation by rape victims", The American Journal of Orthopsychiatry 49(4), 1979, pp. 670-679.

[45] Lipkus, I., "The construction and preliminary validation of a global belief in a just world scale and the exploratory analysis of the multidimensional belief in a just world scale", Personality and Individual Differences 12(11), 1991, pp. 1171-1178.

[46] Majchrzak, A., S. Faraj, G.C. Kane, and B. Azad, "The Contradictory Influence of Social Media Affordances on Online Communal Knowledge Sharing”, Journal of Computer-Mediated Communication 19(1), 2013, pp. 3855.

[47] Mendes, K., J. Ringrose, and J. Keller, "\#MeToo and the promise and pitfalls of challenging rape culture through digital feminist activism", European Journal of Women's Studies 25(2), 2018, pp. 236-246.

[48] Merkin, D., "Opinion | Publicly, We Say \#MeToo. Privately, We Have Misgivings.", The New York Times, 2018.

https://www.nytimes.com/2018/01/05/opinion/goldenglobes-metoo.html

[49] Miller, D.T., "Altruism and threat to a belief in a just world”, Journal of Experimental Social Psychology 13(2), 1977, pp. 113-124.

[50] Miranda, S.M., A. Young, and E. Yetgin, “Are Social Media Emancipatory or Hegemonic? Societal Effects of Mass Media Digitization in the Case of the SOPA Discourse", MIS Quarterly 40(2), 2016, pp. 303-329. [51] Moqbel, M., and N. Kock, "Unveiling the dark side of social networking sites: Personal and work-related consequences of social networking site addiction", Information \& Management 55(1), 2018, pp. 109-119. [52] Moreno-Jiménez, P., "Citizen participation according to causal perceptions of third-world poverty, belief in a just world and gender system justification", Australian Journal of Psychology 68(2), 2016, pp. 82-90.

[53] Oh, O., C. Eom, and H.R. Rao, "Research Note-Role of Social Media in Social Change: An Analysis of Collective Sense Making During the 2011 Egypt Revolution", Information Systems Research 26(1), 2015, pp. 210-223.

[54] Pirkkalainen, H., and M. Salo, "Two Decades of the Dark Side in the Information Systems Basket : Suggesting Five Areas For Future Research", Proceedings of the 24th European Conference on Information Systems, (2016). [55] RadarOnline, "Invasion Of Privacy Is No Joke: A History Of The Erin Andrews Peephole Scandal.", RadarOnline, 2018.

https://radaronline.com/exclusives/2018/05/erin-andrewsnude-peephole-video/ 
[56] Rubin, Z., and A. Peplau, "Belief in a Just World and Reactions to Another's Lot: A Study of Participants in the National Draft Lottery1", Journal of Social Issues 29(4), 1973, pp. 73-93.

[57] Rubin, Z., and L.A. Peplau, "Who Believes in a Just World?”, Journal of Social Issues 31(3), 1975, pp. 65-89. [58] Sayej, N., "Alyssa Milano on the \#MeToo movement: 'We're not going to stand for it any more", The Guardian, 2017.

https://www.theguardian.com/culture/2017/dec/01/alyssamilano-mee-too-sexual-harassment-abuse

[59] Schafer, S., The victim and his criminal: a study in functional responsibility, Random House, 1968.

[60] Selander, L., and S.L. Jarvenpaa, "Digital Action Repertoires and Transforming a Social Movement Organization”, MIS Quarterly 40(2), 2016, pp. 331-352.

[61] Strelan, P., "The prosocial, adaptive qualities of just world beliefs: Implications for the relationship between justice and forgiveness", Personality and Individual Differences 43(4), 2007, pp. 881-890.

[62] Tarafdar, M., J. DArcy, O. Turel, and A. Gupta, "The Dark Side of Information Technology", MIT Sloan

Management Review; Cambridge 56(2), 2015, pp. 61-70.

[63] Tencent, "Tencent", Tencent, 2019.

https://www.tencent.com/en-us/abouttencent.html

[64] Treem, J.W., and P.M. Leonardi, "Social media use in organizations: Exploring the affordances of visibility, editability, persistence, and association", Communication yearbook 36, 2012, pp. 143-189.

[65] Turel, O., and A. Serenko, "The benefits and dangers of enjoyment with social networking websites", European Journal of Information Systems 21(5), 2012, pp. 512-528.
[66] Twitter, "Twitter Values", Twitter, 2019. https://about.twitter.com/en_us/values.html [67] Vaast, E., H. Safadi, L. Lapointe, and B. Negoita, "Social Media Affordances for Connective Action: An Examination of Microblogging Use During the Gulf of Mexico Oil Spill”, MIS Quarterly 41(4), 2017, pp. 11791205.

[68] White, K., R. MacDonnell, and J.H. Ellard, "Belief in a Just Word Consumer Intentions and Behaviors Toward Ethical Products", Journal of Marketing 76(1), 2012, pp. 103-118.

[69] Wilson, .E., and P.R. Darke, "The Optimistic Trust Effect: Use f Belief in a Just World to Cope with DecisionGenerated Threat", Journal of Consumer Research 39(3), 2012, pp. 615-628.

[70] Yang, G., "Narrative Agency in Hashtag Activism: The Case of \#BlackLivesMatter", Media and

Communication, 2016, pp. 13-17.

[71] Yee, V., "Statutory Rape, Twitter and a Connecticut Town's Divide", The New York Times, 2018.

https://www.nytimes.com/2013/04/05/nyregion/generationa 1-divide-in-torrington-conn-over-sex-assault-case.html [72] Zaleski, K.L., K.K. Gundersen, J. Baes, E. Estupinian, and A. Vergara, "Exploring rape culture in social media forums", Computers in Human Behavior 63, 2016, pp. 922-927.

[73] "Opinion: Make 'revenge porn' a crime in U.S.", CNN, 2014.

https://www.cnn.com/2013/08/29/opinion/citron-revengeporn/index.html 